Bounded Love of Variety and Patterns of Trade Philip Sauré

궁
ㅇํㅇ

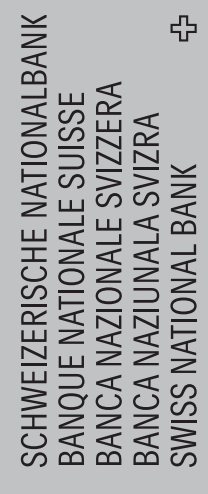

U

(1)

(4)

ro

ค

$\frac{1}{2}$

a

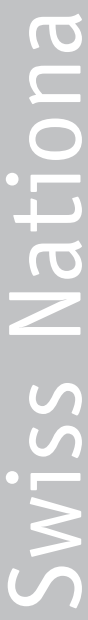


The views expressed in this paper are those of the author(s) and do not necessarily represent those of the Swiss National Bank. Working Papers describe research in progress. Their aim is to elicit comments and to further debate.

\section{Copyright ${ }^{\odot}$}

The Swiss National Bank (SNB) respects all third-party rights, in particular rights relating to works protected by copyright (information or data, wordings and depictions, to the extent that these are of an individual character). SNB publications containing a reference to a copyright ( $\odot$ Swiss National Bank/SNB, Zurich/year, or similar) may, under copyright law, only be used (reproduced, used via the internet, etc.) for non-commercial purposes and provided that the source is mentioned. Their use for commercial purposes is only permitted with the prior express consent of the SNB.

General information and data published without reference to a copyright may be used without mentioning the source.

To the extent that the information and data clearly derive from outside sources, the users of such information and data are obliged to respect any existing copyrights and to obtain the right of use from the relevant outside source themselves.

\section{Limitation of liability}

The SNB accepts no responsibility for any information it provides. Under no circumstances will it accept any liability for losses or damage which may result from the use of such information. This limitation of liability applies, in particular, to the topicality, accuracy, validity and availability of the information.

ISSN 1660-7716 (printed version)

ISSN 1660-7724 (online version)

๑ 2009 by Swiss National Bank, Börsenstrasse 15, P.0. Box, CH-8022 Zurich 


\title{
Bounded Love of Variety and Patterns of Trade*
}

\author{
Philip Sauré ${ }^{\dagger}$ \\ Swiss National Bank
}

November 9, 2009

\begin{abstract}
Recent trade data exhibit the following four empirical regularities: (i) countries import only a small fraction of all traded varieties (ii) per capita income and the number of imported varieties correlate positively (iii) per capita income and trade shares correlate positively and, finally, (iv) world trade shares have increased substantially. The present paper argues that standard theories fail to explain at least some of these patterns and subsequently shows that a small and reasonable change in the demand structure can reconcile the New Trade model with the data. Its key assumption imposes an upper bound on consumers' marginal utility from varieties. This implies that consumers purchase only the cheaper share of varieties, while expensive foreign varieties bearing high transport costs are not consumed. Technological progress that increases per capita consumption of those varieties in the consumption basket decreases marginal utility derived from them and induces consumers to extend their consumption to more expensive varieties produced at distant locations. Through this additional margin trade shares increase as productivity grows. Productivity growth is thus identified as a joint determinant of trade shares, the number imported varieties, and per capita income.
\end{abstract}

Keywords: Marginal Utility, Variety.

JEL Classifications: F10, F13.

\footnotetext{
*I would like to thank Raphael Auer, Giancarlo Corsetti, Gino Gancia, Omar Licandro, Marco Maffezzoli, Diego Puga, Morten Ravn, Karl Schlag, Jaume Ventura, Joachim Voth and an anonymous referee for many valuable comments. All remaining errors are mine.

${ }^{\dagger}$ Swiss National Bank, Börsenstrasse 15, 8048 Zurich, Switzerland. E-mail: Philip.Saure@snb.ch The views expressed in this paper are the author's and do not necessarily represent those of the Swiss National Bank.
} 


\section{Introduction}

Recent trade data exhibit the following four empirical regularities: (i) countries import only a small fraction of all traded varieties (ii) per capita income and the number of imported varieties correlate positively (iii) per capita income and trade shares correlate positively and, finally, (iv) world trade shares have increased substantially. These patterns are both, well known and well studied. Yet, existing explanations typically rely on intricate models to address one of the patterns, while falling short on at least one of the others.

The present paper does not pretend to be the first in addressing the four stylized facts. Instead, its contribution is to show that they emerge naturally within the most basic model with trade in varieties - the Krugman (1980) model - under a small and reasonable modification of consumers' demand structure.

As its key deviation from the standard framework, the present paper imposes that marginal utility be bounded. More precisely, as consumption levels of any given variety drop to zero, marginal utility of its consumption stays finite - instead of approaching infinity as under standard preferences. This twist in the demand structure implies that consumers buy only the cheaper fraction of varieties and exclude the relatively expensive ones - i.e., the foreign varieties that are subject to heavy trade costs - from their consumption basket. Consequently, bilateral trade relations can be zero (pattern (i)). Further, an increase in per capita income, brought about by a decrease of marginal production cost, increases consumption levels of varieties in the consumption basket and marginal utility derived from each of them falls. The varieties outside the consumption basket - the expensive foreign ones - become relatively more attractive. Thus, richer consumers include new foreign varieties in their consumption basket and thereby increase their expenditure share on imports. This jointly explains patters (ii) and (iii). Finally, the positive effect of per capita income growth on world trade shares contributes to explaining the overall growth in world trade shares - pattern (iv).

The above-mentioned empirical regularities mentioned have not gone unnoticed in trade literature. Defining varieties as goods differentiated by production origin ${ }^{1}$, Haveman and Hummels (1999) observe that most importers purchase a very small fraction of the varieties available, concluding that the "complete specialization model considerably overstates the extent of specialization [...] or the degree to which consumers value varieties." Helpman et al (2008) show that a framework of heterogeneous firms and fixed cost of exporting à la Melitz (2003) generate zero trade flows when fixed costs of exporting exceed potential operating profits in export markets. The authors then successfully estimate their predictions, in particular the probabilities of positive bilateral trade flows for a given country

\footnotetext{
${ }^{1}$ This is a common definition of variety, which departs form the earlier definition by Krugman (1980) identifying a variety by the firm that produces it.
} 

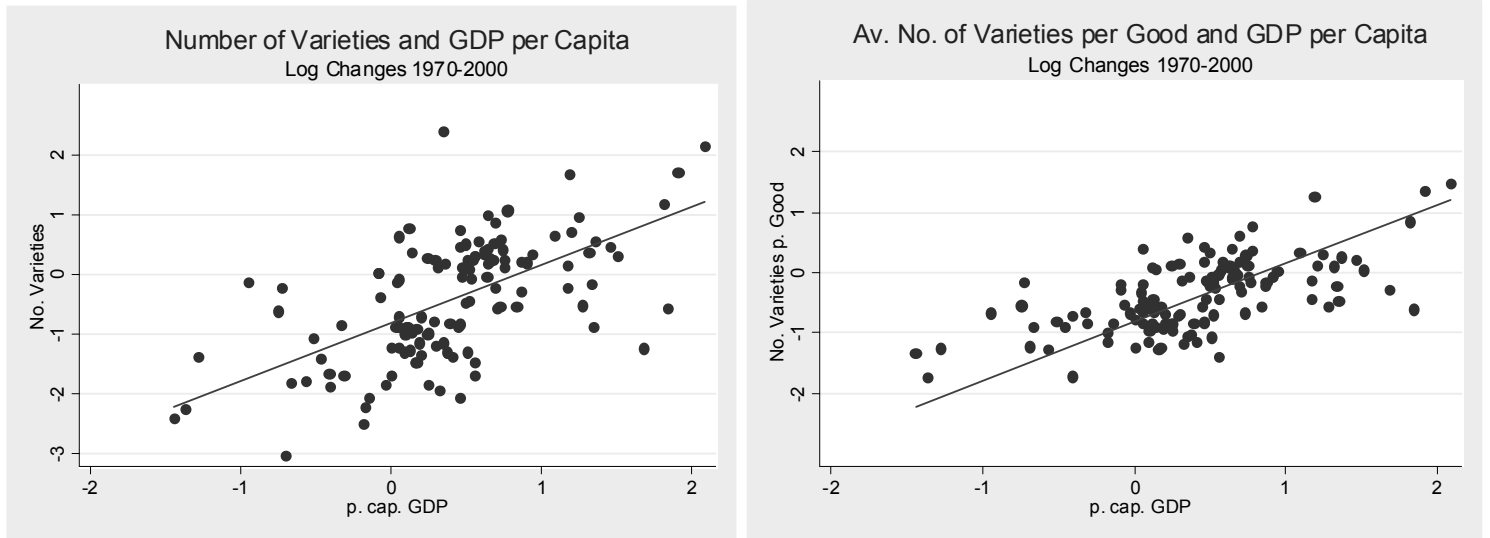

Data Source: Feenstra et al (2005) and PWT6.2

Figure 1: Postitve Correlation between growth in Number of Imported Varieties and per Capita Income. (Log-changes 1970-2000).

pair. While making significant progress in this dimension, however, their model, by relying on homothetic preferences, cannot account for the relation of per capita income and trade shares once total GDP is controlled for (patterns (ii) and (iii)).

Pattern (ii) is the least-known of the empirical regularities. Broda and Weinstein (2004) and (2006) document that from 1970 to 2000 importers generally increased the number of source countries per good. In a related paper Schott (2003) reports that the US "increasingly sources the same products from high- and low-wage countries," which the author attributes to specialization within product categories. Figures 1 and 2 show that the changes in the number of imported varieties strongly correlate with changes in the importer's per capita income. Defining a variety by 4-digit SITC good category and its exporting country, the left panel of Figure 1 shows that within a sample of 129 countries the Log-changes of the importer's per capita income correlates positively with Log-changes in the total number of imported varieties; the right panel establishes a very similar relation between the importer's per capita income and the average number of imported varieties per good ${ }^{2}$. Figure 2 illustrates that the correlation of respective Log-changes hold also of five-year intervals between 1965 and $2000^{3}$.

The third observation, the positive correlation between per capita income and trade shares, is well known but widely neglected. Empirical estimations of the well-known gravity equation find positive effects of per capita income and trade flows. ${ }^{4}$ Indeed, Anderson (1979)

\footnotetext{
${ }^{2}$ A simple OLS regression of Log-changes in the number of varieties (per good) on the Log-changes of importer's GDP per capita renders estimated coefficients of $0.97(0.6)$ with t-statistics for the exogenous variable of 8.51 (9.33) and adjusted R-sq. of $0.36(0.4)$. Controlling for changes in importer's total GDP does not change signs and significance levels. Importantly, total GDP is insignificant, i.e. that market size has little additional explanatory power. See the Appendix for a list of countries.

${ }^{3}$ The splitting into sub-periods decreases the fit of the data but increases the relevant t-statistics.

${ }^{4}$ Hufbauer (1970) provides an early, Francois and Kaplan (1996) more recent empirical study. See also
} 

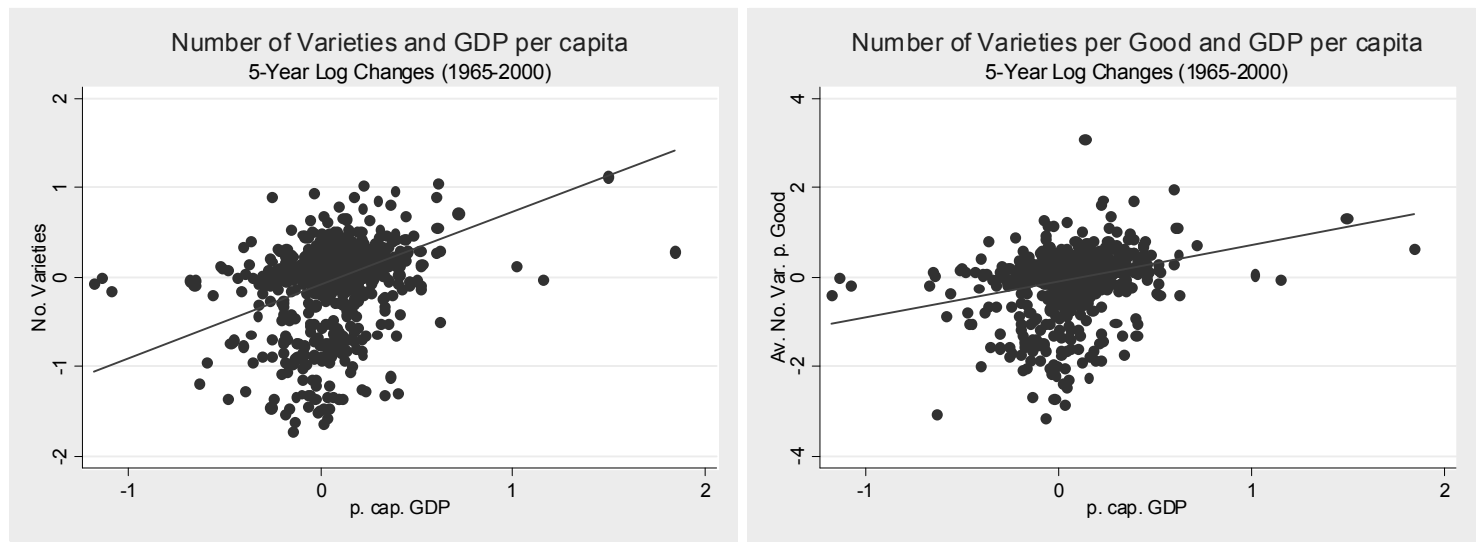

Data Source: Feenstra et al (2005) and PWT6.2

Figure 2: Postitve Correlation between growth in Number of Imported Varieties and per Capita Income (Log-changes of 5-year intervals 1965-2000).

opens his seminal contribution with a specification that accounts for a non-trivial impact of per capita income on trade flows, admitting that, contrary to his model's predictions, "[t]rade shares 'should' increase with income per capita." The high tractability and the resulting analytical elegance of homothetic demand, however, make trade economists usually opt for corresponding preference structures, preventing an independent role of per capita income in the gravity framework once total GDP is controlled for. ${ }^{5}$

The fourth and last of the patterns, the substantial rise in world trade shares, has been intensively studies in recent years. After Krugman's (1995) account of the surprisingly divergent views concerning its causes, Baier and Bergstrand (2001) singled out tariff reductions as its most important determinant. Yi (2003) subsequently argued that the observed increases in world trade shares imply excessive import elasticities in standard trade models (see also Bergoeing et al (2004) on this point). Substantial progress was made in explaining this "elasticity puzzle" as it was later labeled. Yi (2003) argues that increasing international vertical specialization caused the surge in trade volumes by making intermediate good enter trade statistics more than once, thus multiplying trade accounts. Ruhl (2005) puts forward that fixed costs of exporting let more firms enter in reaction to permanent tariff reductions than to transitory exchange rate blips and that this difference accounts for the "elasticity puzzle". Cuñat and Maffezzoli (2006)), finally, show that reductions in trade costs can lead to diverging factor endowments, which adds an amplifying dynamic effect to the well-known static one, thus increasing the impact of tariff reductions under common import elasticities. Yet, by relying on homothetic demand non of these studies accounts for the role of per capita GDP.

\footnotetext{
Ventura (2006) on the correlation between trade volumes and per capita income.

${ }^{5}$ Empirical studies investigating the impact of trade on growth generally control for causal links form income growth to trade openness through various instrumentation techniques (see Frankel and Romer (1999) or Alcalá and Ciccone (2004). Theoretical literature on this point, however, is much less developed.
} 
The current paper adds to these literatures by providing a simple framework that offers a demand-driven explanation of the above-mentioned four empirical regularities. In order to quantitatively evaluate the extend to which it can explain the empirical patterns, the model is calibrated to match the US import shares between 1972 and 2000. This simple exercise shows that, with US tariff reductions, income and population growth from the data the model matches observed US trade shares at a import elasticity that averages around 3.7 (it peaks at an 8.8 in 1972 and is lowest in 2000 with a values of 1.7). This elasticity is still on the high side of estimates empirical estimates but constitutes substantial progress. At the same time, the model does replicates fairly well the increase in the number of varieties per good. As about half of the observed increase in trade volumes is driven by productivity growth - thus correlating with rising income per capita - the assumption of bounded marginal utility can be said to make substantial progress in explaining the above-mentioned empirical regularities.

The present paper is not the first to analyze the role of non-homothetic demand for trade flows. A number studies chose this route to explain the positive correlation of trade shares and per capita income (for empirical studies see Thursby and Thursby (1987) and Françoise and Kaplan (1996); see Hallak (2006) for a related study demand-side based good quality). Closer to the present paper's theoretical approach are Markusen (1986) and Bergstrand (1990) who assume Stone-Geary preferences that make consumers cover a minimum level of a homogenous, domestically produced good before demanding aggregates of imported varieties. The present model does not impose such asymmetries on demand but assumes equal valuation of varieties for consumers, while the cost of transportation creates endogenous asymmetries in demand via its effects on consumer prices. Interestingly, Melitz and Ottaviano (2008) recently propose a multi-country trade model exhibiting non-homothetic preferences, whose elegant framework serves to analyze various models of trade liberalization. While formally part of the class of models with nonhomothetic preferences, its quasi-linear approach is ill-suited to address the link between per capita income and trade patterns as shows in the following section.

Recently, Hummels and Lugovskyy (2005) uses a Lancester-type utility to analyze the role of market size and per capita income on the market structure and international trade. The authors predict - and empirically confirm - that "richer consumers will pay more for varieties closer matched to their ideal types". Consequently, markets characterized by higher per capita income are more segmented and exhibit lower own-price elasticities (market size has opposite effects). Similarly, Simonovska (2009) argues that "rich consumers are less responsive to price changes than poor ones" and combines the present paper's demand structure with a heterogeneous firm framework and to explain positive correlations between prices and per capita income for identical goods. The empirical regularities presented in these studies support the present paper's choice of the specific demand structure.

The remainder of the paper is organized as follows. Section 2 briefly discusses the short- 
coming of existing models in explaining the above-mentioned patterns. Section 3 solves the Krugman (1980) model under non-homothetic demand, discusses the results and calibrates it to US trade data. Finally, section 3 concludes.

\section{Brief Review of Standard Models}

This section discusses two classes of trade models and shows that they fail to generate some of the empirical trade patterns discussed above. The first class of models is based on homothetic demand ${ }^{6}$. The second class rests on quasi-linear utilities. Here, special attention rests on Melitz and Ottaviano (2008), whose model exhibits bounded marginal utility, which might suggest that the present paper's mechanisms might be operating in this earlier contribution.

\subsection{Homothetic Demand}

Thanks to their high analytical tractability, homothetic preferences are the first modelling choice for trade economists. As a characterizing feature of homotheticity, demand of an individual $h \in \mathcal{H}$ with expenditure $E_{h}$ for a good $j \in \mathcal{J}$ can be written as

$$
D_{j}\left(p, E_{h}\right)=g_{j}(p) E_{h}
$$

where $p=\left(p_{1}, p_{2}, \ldots\right)$ is the vector of good prices. The functions $g_{j}($.$) are constant in$ $E_{h}$, non-negative and, by Walras' Law, satisfy $\int_{\mathcal{J}} p_{j} g_{j}(p) d j=1$ for all $p$. Consequently, aggregate demand of a population $\mathcal{H}$ for good $j$ is

$$
\int_{\mathcal{H}} p_{j} D_{j}\left(p, E_{h}\right) d h=p_{j} g_{j}(p) \int_{\mathcal{H}} E_{h} d h=p_{j} g_{j}(p) \bar{E}
$$

where $\bar{E}=\int_{\mathcal{H}} E_{h} d h$ is total expenditure. Thus, aggregate demand for good $j$ is independent of population size, income per capita or income distribution, once total expenditure is controlled for. Denoting the set foreign goods by $\mathcal{J}_{f} \subset \mathcal{J}$, the trade share is

$$
e=\int_{\mathcal{J}_{f}} p_{j} g_{j}(p) d j
$$

and therefore independent of per capita income. Similarly, the mass of imported varieties is

$$
n=\int_{\mathcal{J}_{f}} d j
$$

\footnotetext{
${ }^{6}$ Among the papers mentioned in the introduction, this class comprises Anderson (1979), Baier and Bergstrand (2001), Yi (2003), Melitz (2003), Broda and Weinstein (2004) and (2006), Ruhl (2005), Cuñat and Maffezzoli (2006), Simonovska (2009).
} 
This expression, too, is independent of per capita income. ${ }^{7}$ These observations imply that models imposing homothetic demand are unable to replicate patterns (ii) and (iii).

\subsection{Quasi-Linear demand}

Consider next models where consumers $h \in \mathcal{H}$ derive the quasi-linear utility

$$
u\left(\left\{q_{0 j}\right\}, q_{0}\right)=v\left(\left\{c_{j}\right\}\right)+q_{0}
$$

where $c_{j}$ is consumption variety $j \in \mathcal{J}$ and $q_{0}$ that of a homogeneous good, which is competitively produced under constant returns to scale. Denoting prices of variety $j$ with $p_{j}$ and taking $d$ as the nummeraire, consumer $h$ 's optimization implies $\partial_{c_{k}} v^{\prime}\left(\left\{c_{h j}\right\}\right) \leq p_{k}$ $\left(c_{h j}>0\right.$ implies equality). Importantly, consumption $c_{h j}=\bar{c}_{j}$ is independent of individual $h$ 's expenditure $E_{h}$. Thus, a population $\mathcal{H}$ of $L$ individuals with the total expenditure $\bar{E}=\int_{\mathcal{H}} E_{h} d h$ allocates the amount $\bar{E}_{j}=p_{j} \bar{c}_{j} L$ on consumption of variety $j$. This term is independent of per capita income (corner solutions being generally ruled out). Since demand elasticities and market size are the only demand-side determinants of profits, the firms' export decision to a given market and the according export volume are independent of per capita income. Thus, income growth that leaves relative prices $p_{j}$ constant predicts that the number of varieties a country imports $\left(\mathcal{J}_{f} \subset \mathcal{J}\right)$

$$
n=\int_{\mathcal{J}_{f}} d j
$$

is independent of per capital income. At the same time, as $p_{j}$ and $\bar{c}_{j}$ are constant, a country's expenditure on traded varieties

$$
e=\frac{L}{\bar{E}} \int_{\mathcal{J}_{f}} p_{j} \bar{c}_{j} d j
$$

decreases as per capita expenditure $\bar{E} / L$ rise.

The assumption that relative prices are constant is admittedly strong. In particular, productivity growth that generate growth of per capita income might decreases the prices of varieties by relatively more than the price of the homogeneous good. It is therefore worth to take a closer look at the framework of Melitz and Ottaviano (2008), considering a reduction in production costs by multiplying the parameter $c_{M}$ that governs costs in (14) by the factor $\theta \in(0,1)^{8}$. The same drop in production costs is assumed to affect production of the homogeneous good $\left(q_{0}\right)$. To preserve $q_{0}$ as the nummeraire as well as unit wages, however, this drop is modeled as a multiplication of $q_{0}$ by $\theta^{-1}$ in the specific

\footnotetext{
${ }^{7}$ By the same token, the set of countries an importer purchases from - on which the definition of variety is based in Figures 1 and 2 - is constant in per capita income.

${ }^{8}$ All referencing to equations in this subsection refers to Ottaviano and Melitz (2008).
} 
utility function

$$
u=q_{0}+\alpha \int q_{j} d j-\frac{\gamma}{2} \int q_{j}^{2} d j-\frac{\eta}{2}\left(\int q_{j} d j\right)^{2}
$$

or, equivalently, a multiplication of $\alpha, \eta$ and $\gamma$ by $\theta$. With the equations (22) and (23) this implies that the cost cut-off $c_{D}$ decreases at rate $\theta^{(k+1) /(k+2)}$, i.e. slower than $\alpha$. Thus, a quick glance at a symmetric version of Melitz and Ottaviano's (2008) two country model shows that the total number of firms selling into each market (24) actually decreases under productivity growth. Moreover, by (14) and (19) the share of exporting firms is constant $\left(G\left(c_{D} / \tau\right) / G\left(c_{D}\right) \equiv \tau^{-k}\right)$ so that the number of exporting firms $N$ decreases too. Finally, integrating revenues in foreign market $r(\tau c)$ from (10) from 0 to the export cut-off $c_{D} / \tau$ over the density (14) leads the expenditure share on imported varieties

$$
e=\frac{\tau^{-k} N}{L} \int_{0}^{c_{D} / \tau} r(\tau c) d G(c)=\tau^{-k} N \frac{1}{4 \gamma} c_{D}^{2}
$$

(Nominal wages were held constant by construction.) Since $c_{D}$ decreases by the factor $\theta^{(k+1) /(k+2)}$ the product $\gamma c_{D}^{2}$ shrinks by the factor $\theta^{k /(k+2)}$. As, finally, $N$ is decreasing in productivity growth (of cost-reduction), the overall picture is that within the Melitz and Ottaviano (2008) model $e$ tends to fall as productivity grows.

\section{Love of Variety with Bounded Marginal Utility}

This section shows with a small change in the demand structure Krugman's (1980) New Trade Model performs fairly well in explaining the four empirical regularities outlined in the introduction.

Demand. There are $i \in I$ countries, each populated with identical individuals who derive utility from a nontradable good $D_{i}$ and a composite of tradable varieties $C_{i}$

$$
U_{i}=D_{i}^{1-\gamma} C_{i}^{\gamma}
$$

The composite $C_{i}$ aggregates consumed quantities $c_{i j}$ of the varieties $j \in J$. Within the composite of tradables $C_{i}$ consumers value variety but, in contrast to the standard CES setup, marginal utility derived from each of the varieties is bounded. Preference structures with this characteristic have been used to study topics in trade literature and it will be convenient to follow an important precursor by assuming with Young (1991) that the composite of varieties takes the form

$$
C_{i}=\int_{J} \ln \left(c_{i j}+1\right) d j
$$

where $c_{i j}$ is quantity of variety $j$ consumed by an individual in country $i$. In this particular 
setup, the marginal sub-utility derived from consumption of variety $j$ never exceeds unity. ${ }^{9}$ Equilibrium demand is derived by maximizing utility (2) subject to the sub-budget constraint

$$
\int_{J} q_{i j} c_{i j} d j \leq \gamma w_{i}
$$

where $q_{i j}$ is the consumer price of the variety $j$ in country $i$. Maximization renders

$$
c_{i j}=\max \left\{1 /\left(\lambda_{i} q_{i j}\right)-1,0\right\}
$$

where $\lambda_{i}$ stands for the shadow price on the sub-budget constraint (3). The demand curve (4) carries already the flavor of the present model's mechanism: it shows that consumers in any country $i$ demand the varieties with the lowest local price $q_{i j}$ first. Moreover, in presence of substantial trade costs, the cheap varieties tend to be those produced domestically. Yet, as consumption levels of cheap varieties increase, the consumers' inclination to pay higher prices for additional varieties rises and, consequently, the bundle of consumed - and imported - varieties increases. Figure 3 illustrates the effect of an income raise. plotting consumed quantities (vertical axis) against the index $j \in J$ of varieties (horizontal axis). Varieties are ordered according to ascending prices so that consumption is positive for $j<j_{o}$ only (bold line). An increase in total expenditure at constant prices (a shift to the dashed line) increases consumption levels for $j<j_{o}$ and induces an increase form $j_{o}$ to $j_{1}$. When expensive varieties are identified with imported varieties, this implies that the bundle of imported varieties grows and, at the same time, the expenditure share on imports increases.

Finally, notice that the generic demand curve (4) implies that either two varieties $c_{i j}$ and $c_{i l}$ consumed in positive quantities the identity

$$
\frac{1+c_{i j}}{1+c_{i l}}=\frac{q_{i l}}{q_{i j}}
$$

holds.

Supply. In each country the nontradable good $D$ is produced competitively with a constant returns to scale technology

$$
D=L_{D}
$$

The tradable varieties are produced according to the increasing returns to scale technology

$$
L_{j}=\alpha+\beta_{j} x_{j}
$$

\footnotetext{
${ }^{9}$ The transformation $\tilde{c}=c / \vartheta(\vartheta>0)$ implies $\ln (\tilde{c}+1)=\ln (1 / \vartheta)+\ln (c+\vartheta)$ and shows that, as long as consumption units are free, the coice of adding unity instead of a positive constant does not mean a loss of generality.
} 


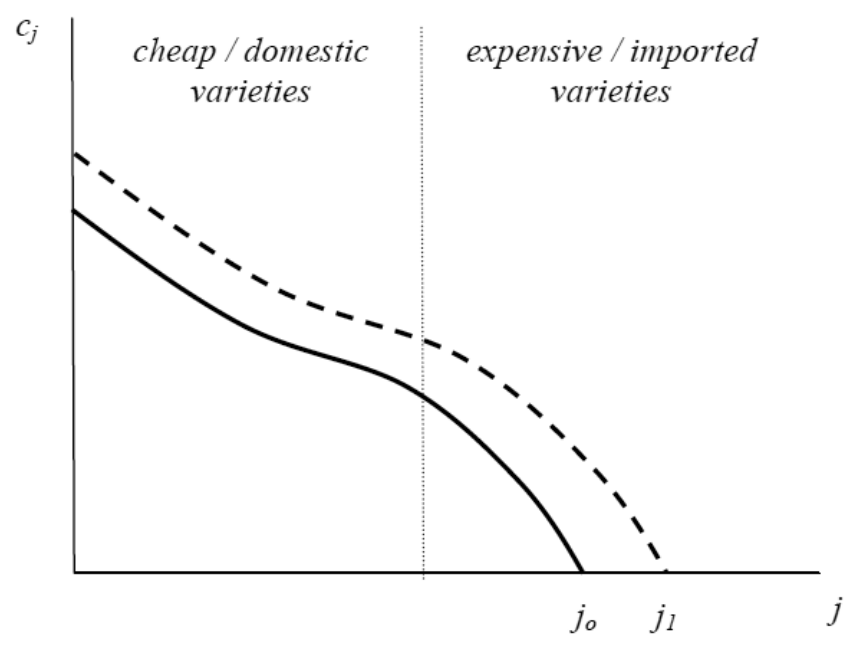

Figure 3: Demand under Bounded Marginal Utility

where $L_{j}$ is labor and $x_{j}$ is output of firm $j$. The parameter $\alpha$ represents an entry cost to production measured in labor units; $\beta_{j}$ is the marginal unit labor requirement. There is an unlimited pool of potential entrants into the market and each active firm produces one variety. Firms engage in monopolistic competition, and free entry into production ensures that operating profits cover the setup cost.

Pricing. In the competitive nontradable sector prices trivially equal wages. In the tradable sector, firms price-discriminate across different countries so that a firm $j$ sets the price $p_{i j}$ for market $i$ in order to maximize its operating profits $\pi_{i j}$ in that specific market. When firm $j$ is located in country $k$ and gross iceberg-type trade costs between country $k$ and country $i$ are $\tau_{k i} \geq 1$, the consumer price in country $i$ of variety $j$ is the $q_{i j}=\tau_{k i} p_{i j}$. In the market $i$ firm $j$ makes the profit of $\pi_{i j}=L_{i} \tau_{k i} c_{i j}\left(p_{i j}-w_{k} \beta_{k}\right)$, where $L_{i}$ is the number of individuals in the market $i$ and $w_{k}$ is the wage in country $k$ (i.e. $w_{k} \beta_{k}$ is the marginal cost of production). With local demand (4), firm $j$ 's profits are thus

$$
\pi_{i j}=L_{i} \tau_{k i}\left(1 /\left(\lambda_{i} \tau_{k i} p_{i j}\right)-1\right)\left(p_{i j}-w_{k} \beta_{k}\right)
$$

Generic profit maximization implies

$$
p_{i j}=\sqrt{w_{k} \beta_{k} /\left(\lambda_{i} \tau_{k i}\right)}
$$

for each market $i$ separately. With the expression (4) this price can be written as

$$
p_{i j}=\left(c_{i j}+1\right) w_{k} \beta_{k}
$$

Notice that markup over marginal cost equals $c_{i j}+1$, corresponding to the demand elas- 
ticity from (4), which equals

$$
\varepsilon_{i j}=\left(c_{i j}+1\right) / c_{i j} .
$$

The demand structure assumed in (2) thus implies that the own-price elasticity of varieties depends on quantities consumed ${ }^{10,11}$.

Free Entry. Firms within each country face the same production costs and charge the identical prices in a given market so that the index of the representative firm of a country can be indexed with the country index $k$ itself. Combining (8) and (9) the profits a firm in country $k$ makes by selling to country $i$ are

$$
\pi_{i k}=L_{i} \tau_{k i} w_{k} \beta_{k} c_{i k}^{2}
$$

Under free entry to production, total operating profits, i.e. the sum of a firm's profits in each market, are equal to setup costs:

$$
\sum_{i} L_{i} \tau_{k i} \beta_{k} c_{i k}^{2}=\alpha
$$

for all countries $k$.

Labor Market Clearing. Consumers spend constant fraction $1-\gamma$ on the nontradable good $D$ and, consequently, the same fraction $1-\gamma$ of workers is employed in the nontradable sector. The resource constraint in the remaining, tradable, sector requires then

$$
n_{k}\left[\left(\sum_{i} L_{i} \tau_{k i} c_{i k}\right) \beta_{k}+\alpha\right]=\gamma L_{k}
$$

Combinign this equation with (12) leads to

$$
n_{k} \beta_{k}\left[\sum_{i} L_{i} \tau_{k i}\left(c_{i k}+1\right) c_{i k}\right]=\gamma L_{k}
$$

for all countries $k$. (Notice that formally, summation in (13) runs over all trade partners $k$, including those with zero exports to country $i\left(c_{i k}=0\right)$.)

\subsection{Closed Economy}

Whenever international transport costs are prohibitive the trans-border trade runs dry. This case can be analyzed by looking at one representative closed economy, within which

\footnotetext{
${ }^{10}$ The present paper's motivation partly rests on the "elasticity-puzzle", i.e. on the discrepancy between measured import elasticities and the observed rise in trade volumes. Thus, a calibration of the model will be necessary to asses the implied import elasticities at observed trade shares.

${ }^{11}$ In line with the estimates in Haveman and Hummels (2004), preferences specified in (2) predict higher markups at higher per capita consumption levels.
} 
transport costs are assumed to be negligible $\left(\tau_{i i}=1\right)$. Dropping country indices, the representative firm in an autarkic economy sets its price according to (9):

$$
p=(c+1) w \beta,
$$

its operating profit (11) is

$$
\pi=w \beta L c^{2}
$$

and profits (11) together with the free entry condition (12) determine the quantities consumed per individual and per variety:

$$
c=\sqrt{\frac{\alpha}{\beta L}}
$$

Equation (16) shows that, quite intuitively, an increase in setup over marginal costs $(\alpha / \beta)$ increases per capita consumption of the average variety. At higher values of $\alpha / \beta$, varieties are relatively costly to invent, so that less different varieties exist and per capita consumption of each of them is high. Conversely, if population size $L$ increases, demand for varieties is high, which increases the number of active firms and reduces per capita consumption of each single variety.

The equilibrium number of active firms, $n$, is finally determined by labor market clearing (13) and goods market clearing $(x=L c)$ :

$$
n=\frac{\gamma L}{\alpha+\sqrt{\alpha \beta L}}
$$

Notice that the number of active firms is determined by technology parameters, the market size and population. The difference between the two latter parameters is noteworthy. Market size, defined as total expenditure on varieties $(\gamma L)$, enters the number of firms linearly, so that a one percent increase in market size induces a one percent rise in the number of active firms. (This first effect is the only one under CES preferences.) Population size, however, has an additional effect on the number of firms, which it tends to reduce when the market size is held fixed.

For an intuition of this second effect, compare two economies, the first with twice the labor force but half the parameter $\gamma$ of the second. Expenditure on varieties $c_{j}$ is identical in both economies, yet per capita expenditure of the former economy is half of the latter $\left(\gamma_{1}=\gamma_{2} / 2\right.$ and $\left.L_{1}=2 L_{2}\right)$. Now, if the number of firms happened to be equal, consumption per capita and per variety in the first economy would be lower than in the second. Consequently, firm markups would be lower in the first economy as demand elasticity decreases with per capita consumption by (10). This, in turn, implies that operating profits would be strictly lower in the first economy, thus violating the free entry condition. Instead, in the first economy with higher demand elasticity, and lower markups require 
that the total number of firms be lower. This mechanism explains the negative impact of $L$ on $n$ in (17) once $\gamma L$ is controlled for.

In sum, the overall effect of an increase in population $L$ on the number of firms is still positive, but, due to the demand effects discussed above, an increase in population size induces a less than proportional increase in the number of firms and thus increases per capita consumption of the average variety.

Before closing this section, it is instructive to consider the necessary condition for autarky to prevail. A given pair of countries does not engage in cross-border trade if at a virtual level of relative wage $w^{*} / w$ and autarky consumption level (9) consumers in at least one country do not demand foreign varieties. When variables of one country are marked with an asterisk, these conditions are,

$$
\frac{c+1}{1} \leq \frac{\tau w^{*} \beta^{*}}{(c+1) w \beta} \quad \text { or } \quad \frac{c^{*}+1}{1} \leq \frac{\tau w \beta}{\left(c^{*}+1\right) w^{*} \beta^{*}} \quad \forall \frac{w^{*}}{w}>0 .
$$

where $c=\sqrt{\alpha /(\beta L)}$ and $c^{*}=\sqrt{\alpha /\left(\beta^{*} L^{*}\right)}$ according to (16). This condition can be summarized by

$$
(\sqrt{\alpha /(\beta L)}+1)\left(\sqrt{\alpha /\left(\beta^{*} L^{*}\right)}+1\right) \leq \tau
$$

Obviously, when trade costs $\tau \geq 1$ drop to levels close enough to unity, condition (18) is violated and the two countries engage in international trade. Similarly, when marginal productivity $\left(1 / \beta^{(*)}\right)$ in at least one country grows large enough, consumption per capita and per variety (16) in this country rises up to a point where local consumers are willing purchase the more costly foreign varieties. Thus, either reductions in trade costs or rising marginal productivity can generate trade. To analyze either case, consider a two-country economy next.

\subsection{The Two-Country Model}

Consider a pair of countries and assume that trade costs are low enough or marginal productivities are high enough to generate positive cross-border trade. To simplify the notation the variables of the second of the countries will be marked by an asterisk. Individuals in one country can purchase varieties produced in the other. Yet, for every unit of a variety to arrive at its destination, $\tau>1$ units of it have to leave the producer's country.

As firms price discriminate between countries their prices are summarized by the pair $\left(p_{d}, p_{f}\right)$ for firms located in country 1 and $\left(p_{d}^{*}, p_{f}^{*}\right)$ for firms located in country 2 . Denote the quantities consumed in the respective country by $\left(c_{d}, c_{f}\right)$ and $\left(c_{d}^{*}, c_{f}^{*}\right)$. The necessary and sufficient condition for bilateral trade flows to be zero (18) has been derived in the previous subsection. Consequently, under positive trade flows $\left(c_{f}, c_{f}^{*}>0\right)$ the inequality 
(18) must be violated. If this is the case (16), implies

$$
\frac{c_{d}+1}{c_{f}+1} \geq \sqrt{\tau \frac{w^{*} \beta^{*}}{w \beta}} \text { and } \frac{c_{d}^{*}+1}{c_{f}^{*}+1} \geq \sqrt{\tau \frac{w \beta}{w^{*} \beta^{*}}}
$$

The first (second) condition holds with equality whenever $c_{d}>0\left(c_{d}^{*}>0\right)$. Notice also that together both inequalities imply

$$
\frac{c_{d}+1}{c_{f}+1} \frac{c_{d}^{*}+1}{c_{f}^{*}+1} \geq \tau
$$

so that, by $\tau \geq 1$ either $c_{d}$ or $c_{d}^{*}$ is strictly positive. Now, according to (9) the firms' optimal price in the respective markets are

$$
\begin{array}{ll}
p_{d}=\left(c_{d}+1\right) w \beta & p_{d}^{*}=\left(c_{d}^{*}+1\right) w^{*} \beta^{*} \\
p_{f}=\left(c_{f}^{*}+1\right) w \beta & p_{f}^{*}=\left(c_{f}+1\right) w^{*} \beta^{*}
\end{array}
$$

and the corresponding profits (11) are

$$
\begin{array}{ll}
\pi_{d}=L w \beta c_{d}^{2} & \pi_{d}^{*}=L^{*} w^{*} \beta^{*}\left(c_{d}^{*}\right)^{2} \\
\pi_{f}=L^{*} \tau w \beta\left(c_{f}^{*}\right)^{2} & \pi_{f}^{*}=L \tau w^{*} \beta^{*} c_{f}^{2}
\end{array}
$$

Free entry conditions in both countries imply

$$
c_{d}=\sqrt{\frac{\alpha / \beta-L^{*} \tau\left(c_{f}^{*}\right)^{2}}{L}} \quad \text { and } \quad c_{d}^{*}=\sqrt{\frac{\alpha / \beta^{*}-L \tau c_{f}^{2}}{L^{*}}}
$$

With the prices $(21)$ the trade balance $\left(n L^{*} \tau p_{f} c_{f}^{*}=n^{*} L \tau p_{f}^{*} c_{f}\right)$ is

$$
n L^{*}\left(c_{f}^{*}+1\right) w \beta c_{f}^{*}=n^{*} L\left(c_{f}+1\right) w^{*} \beta^{*} c_{f}
$$

The two countries' resource constraints from (13) are

$$
n\left[\left(L c_{d}+L^{*} \tau c_{f}^{*}\right) \beta+\alpha\right]=\gamma L \quad \text { and } \quad n^{*}\left[\left(L^{*} c_{d}^{*}+L \tau c_{f}\right) \beta^{*}+\alpha\right]=\gamma L^{*}
$$

and can be used to eliminate $n$ and $n^{*}$ in the trade balance. This leads to the following expression for relative wages

$$
\frac{w^{*}}{w}=\frac{c_{f}^{*}+1}{L c_{d} / c_{f}^{*}+L^{*} \tau+\alpha /\left(\beta c_{f}^{*}\right)}\left[\frac{c_{f}+1}{L^{*} c_{d}^{*} / c_{f}+L \tau+\alpha /\left(\beta^{*} c_{f}\right)}\right]^{-1}
$$

Substituting $c_{d} c_{d}^{*}$ from (23) makes the expression on the right of (26) (the RHS) a function $c_{f}^{*}$ and $c_{f}$ only, which is, moreover, increasing in $c_{f}^{*}$ and decreasing in $c_{f}$.

Since optimality condition (20) showed that either $c_{d}$ or $c_{d}^{*}$ is strictly positive, the two 
cases $c_{d}>0$ and $c_{d}^{*}>0$ are to be distinguished by combining, respectively, the binding conditions in (19) with the trade balance (26). Making use of (23) leads to ${ }^{12}$

$$
\frac{\left[L^{*} \sqrt{\frac{\alpha /\left(\beta^{*} c_{f}^{2}\right)-L \tau}{L^{*}}}+L \tau\right] \beta^{*}+\alpha / c_{f}}{\left[L \sqrt{\frac{\alpha /\left(\beta\left(c_{f}^{*}\right)\right)^{2}-L^{*} \tau}{L}}+L^{*} \tau\right] \beta+\alpha / c_{f}^{*}}= \begin{cases}\frac{1}{\tau} \frac{\left(\sqrt{\frac{\alpha / \beta-L^{*} \tau\left(c_{f}^{*}\right)^{2}}{L}}+1\right)^{2}}{\left(c_{f}+1\right)\left(c_{f}^{*}+1\right)} & \text { if } c_{d}>0 \\ \tau \frac{\left(c_{f}^{*}+1\right)\left(c_{f}+1\right)}{\left(\sqrt{\frac{\alpha / \beta^{*}-L \tau c_{f}^{2}}{L^{*}}}+1\right)^{2}} & \text { if } c_{d}^{*}>0\end{cases}
$$

Consider now the first case $c_{d}>0$. If $c_{d}^{*}=0$, then (23) implies that $c_{f}$ is constant so that the RHS of (27) is decreasing in $c_{f}^{*}$ while the LHS is increasing in $c_{f}^{*}$. If, instead, $c_{d}^{*}>0$ then (20) holds with equality and (23) implies

$$
\frac{\sqrt{\left(\alpha / \beta^{*}-L \tau c_{f}^{2}\right) / L^{*}}+1}{c_{f}+1}=\tau \frac{c_{f}^{*}+1}{\sqrt{\left(\alpha / \beta-L^{*} \tau\left(c_{f}^{*}\right)^{2}\right) / L}+1}
$$

This equation establishes a negative relation between $c_{f}$ and $c_{f}^{*}$, which implies that the RHS of (27) is decreasing in $c_{f}^{*}$ while the LHS is increasing in $c_{f}^{*}$.

In the second case, where $c_{d}^{*}>0$ holds, consider first the case $c_{d}=0$, implying with (23) that $c_{f}^{*}$ is constant. If $c_{d}>0$, instead, the logic above shows that the the RHS of (27) is decreasing in $c_{f}^{*}$ while the LHS is increasing in $c_{f}^{*}$. Thus, the two-country equilibrium determined by (19), (23), (25) and (27) - is unique.

Finally, the trade share of the first country is $e=\gamma n^{*} \tau p_{f}^{*} c_{f} /\left[n p_{d} c_{d}+n^{*} \tau p_{f}^{*} c_{f}\right]$. Identities (21) and (24), (26) can be used to eliminate prices, wages, and the number of firms to express the trade share in terms of the equilibrium consumption levels:

$$
e=\gamma \frac{\tau L^{*}\left(c_{f}^{*}+1\right) c_{f}^{*}}{L\left(c_{d}+1\right) c_{d}+\tau L^{*}\left(c_{f}^{*}+1\right) c_{f}^{*}}
$$

for the first country's trade share.

\subsection{The Multicountry Model}

To analyze the general multi-country model, we need to describe the set of varieties an individual in a given country $i$ consumes. Since firms within a country are identical, this set of firms is equivalently described by set of country $i$ 's source countries.

\footnotetext{
${ }^{12}$ In the case $c_{d}, c_{d}^{*}>0(20)$ holds with equality and both expressions on the right hand side coincide.
} 
Defining first the origin country of the cheapest varieties in country $i$ as

$$
i_{o}=\underset{k \in I}{\operatorname{argmin}}\left\{\tau_{k i} w_{k} \beta_{k}\right\}
$$

the set of countries country $i$ imports from is

$$
M_{i}=\left\{k \in I \mid c_{i i_{o}}+1>\sqrt{\tau_{k i} w_{k} \beta_{k} /\left(\tau_{i_{o} i} w_{i_{o}} \beta_{i_{o}}\right)}\right\}
$$

where demand (4) and prices (9) have been used. By definition this set of countries that export to country $i$ does not exclude country $i$ itself. Now, for all $k \in M_{i}$

$$
\left(c_{i i_{o}}+1\right)^{2} \tau_{i_{o} i} w_{i_{o}} \beta_{i_{o}}=\left(c_{i k}+1\right)^{2} \tau_{k i} w_{k} \beta_{k}
$$

holds. Notice also that the set $M_{i}$, comprising country $i$ 's source countries, does not necessarily coincide with the set of countries country $i$ exports to. This latter set of export destinations is

$$
E_{i}=\left\{k \in I \mid c_{k k_{o}}+1>\sqrt{\tau_{i k} w_{i} \beta_{i} /\left(\tau_{k_{o} k} w_{k_{o}} \beta_{k_{o}}\right)}\right\}
$$

The definitions of $M_{i}$ and $E_{i}$ rely on equilibrium wages $w_{k}$ and are, at the same time, outcome of the equilibrium. Combining labor market clearing (13)

$$
n_{i} \beta_{i}\left[\sum_{k} L_{k} \tau_{i k}\left(c_{k i}+1\right) c_{k i}\right]=\gamma L_{i}
$$

with the trade balance

$$
n_{i} \sum_{k} L_{k} p_{k i} \tau_{i k} c_{k i}=L_{i} \sum_{k} n_{k} \tau_{k i} p_{i k} c_{i k}
$$

and prices (9) leads to

$$
w_{i}=\sum_{k} w_{k} \frac{L_{k} \tau_{k i}\left(c_{i k}+1\right) c_{i k}}{\sum_{m} L_{m} \tau_{k m}\left(c_{m k}+1\right) c_{m k}}
$$

The multi-country equilibrium consists of a set of consumed quantities $\left\{c_{i k}\right\}_{i, k \in I}$, wages $\left\{w_{i}\right\}_{i \in I}$, number of firms $\left\{n_{i}\right\}_{i \in I}$ and sets of supplied and supplying countries $\left\{E_{i}\right\}_{i \in I}$ and $\left\{M_{i}\right\}_{i \in I}$. These $I(I+2)$ variables are jointly determined by equations (12), (28), (29), (31) and (32).

The system (28) - (32) can be solved numerically. It exhibits, however, a complex interrelation between the sets of trade partners $\left(M_{i}\right.$ and $\left.E_{i}\right)$ and wages $\left(w_{i}\right)$, which stems from the corner solutions in individual optimization $\left(c_{i k}=0\right.$ for $\left.k \notin M_{i}\right)$. Instead of addressing these difficulties analytically, the paper proceeds by strongly simplifying the 
model to symmetry.

\subsubsection{Symmetry}

Assume that all countries are identical in terms of labor force and technologies. Pairs of countries may differ regarding the respective transportation cost they face when engaging in bilateral trade. Yet, to reap the virtues of the symmetry-assumption, countries are supposed to be symmetric in terms of potential trade partners. In particular, the vector of gross iceberg trade cost $\tau_{i}=\left(\tau_{i 1}, \tau_{i 2}, \ldots, \tau_{i I}\right)$ is, up to reordering, identical across countries $i{ }^{13}$ As all parameters that govern demand and supply are - up to permutation - identical across countries, producer prices and wages equalize throughout countries and can be normalized: $w_{i}=w=1$.

The bounded marginal utility from varieties implies, just like in the two-country model, that there is a threshold on the transportation cost $\bar{\tau}$ above which there is no bilateral trade. The defining condition for this threshold is determined by demand (4), prices (9) and autarky consumption (16)

$$
c_{i i}=\sqrt{\alpha /(\beta L)}=\sqrt{\bar{\tau}}-1
$$

(Compare also (18).) Consider now, say, country 1 as the representative country and denote by $M$ the set of countries it purchases varieties from. Under prices (9) the optimal consumer choice requires

$$
c_{11}+1=\sqrt{\tau_{1 k}}\left(c_{1 k}+1\right) \quad k \in M
$$

The profits a firm $j$ located in country 1 makes by selling to market $k \in M$ are (11) and the free entry condition (12) is

$$
\pi_{1}=\sum_{k \in M} \pi_{1 k}=\sum_{k \in M} L \beta\left(c_{11}-\left(\sqrt{\tau_{1 k}}-1\right)\right)^{2}=\alpha
$$

Writing the shorthand

$$
T_{M, 1}=\sum_{k \in M}\left(\sqrt{\tau_{1 k}}-1\right) \quad \text { and } \quad T_{M, 2}=\sum_{k \in M}\left(\sqrt{\tau_{1 k}}-1\right)^{2}
$$

condition (35) leads to an expression for per capita consumption of the domestic varieties:

$$
c_{11}=\frac{T_{M, 1}}{|M|}+\sqrt{\frac{\alpha}{\beta L|M|}+\left(\frac{T_{M, 1}}{|M|}\right)^{2}-\frac{T_{M, 2}}{|M|}}
$$

\footnotetext{
${ }^{13}$ For all $i, k \in I$ there is a permutation $\xi: I \rightarrow I$ so that $\xi\left(\tau_{i}\right)=\tau_{k}$
} 
Here and in the following, $|M|$ stands for the number of country 1's trade partners (elements of $M$ ). Note that $M$ is an endogenous variable that eventually depends on the schedule of bilateral trade costs. Formally, (36) and (37) exhibit a circular definition, as $M$ is defined as

$$
M=\left\{k \in I \mid \sqrt{\tau_{1 k}}<c_{11}+1\right\}
$$

while $c_{11}$ depends on $M$ itself. One can show, however, the following

Proposition 1 The set $M$ is non-empty and uniquely defined by (36) and (37).

Proof. Assume wlog that the elements of the vector $\tau_{1}$ are ordered according to ascending size. Then note that $\tau_{1 l} \leq \tau_{1 k}$ implies $k \in M \Rightarrow l \in M$. Consequently, by (37), any solution to (37) must be of the form $\{1,2, \ldots, n\}$ for one $n \in I$. Now define $c_{n}$ by (36) under $M=\{1,2, \ldots, n\}$ and observe that $c_{n}$ is decreasing in $n$, so that the sequence defined by $m_{n}=\max \left\{k \in I \mid \sqrt{\tau_{1 k}}<c_{n}+1\right\}$ is decreasing in $n$. By monotonicity and since $\{1\} \in M$, there is a unique $n^{*}$ satisfying $m_{n^{*}} \geq n^{*}$ and $m_{n^{*}+1}<n^{*}+1$. By construction the set $\left\{1,2, \ldots, n^{*}\right\}$ solves (37).

With the equilibrium per capita quantities of domestic varieties well defined, equations (34), (35), and the free entry condition $\left(n\left[\alpha+\beta L\left(\sum_{k \in M} \tau_{1 k} c_{1 k}\right)\right]=\gamma L\right)$ determine the number of active firms

$$
n=\frac{\gamma L}{\alpha+\beta L\left[\left(T_{M, 1}+|M|\right) \sqrt{\frac{\alpha}{\beta L|M|}+\left(\frac{T_{M, 1}}{|M|}\right)^{2}-\frac{T_{M, 2}}{|M|}}+\frac{\left(T_{M, 1}\right)^{2}}{|M|}-T_{M, 2}\right]}
$$

Consumers' optimality condition (34) and (36) imply that the trade share of country 1 is

$$
e=\gamma\left[1-\frac{n p_{11} c_{11}}{n p_{11} \sum_{k \in M} \sqrt{\tau_{1 k}} c_{1 k}}\right]=\gamma\left[1-\frac{1}{M}\left(1+\frac{T_{M, 1}}{\sqrt{\frac{\alpha|M|}{\beta L}+\left(T_{M, 1}\right)^{2}-|M| T_{M, 2}}}\right)\right]
$$

The equations (36) - (39) pin down the representative country's number of trade partners and its trade share, the two key trade parameters which the present model aims to explain.

The set of a country's trade partners $M$ depends on the model's parameters and may be any subset of the full set of countries $I$ satisfying $\{1\} \subset M$. Just as in the twocountry world, trade costs can, if they are too high, impede bilateral trade. As discussed in connection with generic demand (4), the inclination to pay for more expensive foreign varieties increases with rising per capita consumption of the domestic varieties. Since per capita consumption of each domestic variety decreases with population size $L$ (more local varieties exist due to market size effects) while it decreases in the ratio $\alpha / \beta$, one may conjecture that these parameters drive the contraction or expansion of the set of trade partners. 
Similarly, the trade share (39) can be expected to fall in $L$ and rise in $\alpha / \beta$ - not only since per capita consumption of foreign varieties increase relatively more than domestic varieties (compare (34)), but also because the set of trade partners expands. The dimension of trade partners - or source countries - constitutes an extra margin along which trade volumes expand and amplifies the first effect.

The above considerations regarding the number of trade partners and the trade share prove right and the impact of population size and technology on these variables is summarized in the following

Proposition 2 Trade share e and number of trade partners $|M|$ increase in $\alpha /(\beta L)$.

Proof. Note first that for any change in the set $M$ condition (34) must be satisfied for the newcomer (dropout). Thus, the trade share as $e=\gamma\left(1-\frac{c_{11}}{|M| c_{11}-T_{M, 1}}\right)$ is continuous at any change in $|M|$. By this observation and by (36) it is sufficient to prove that the equilibrium $c_{11}$ is increasing in $\alpha /(\beta L)$. Using (36), this is trivially the case whenever $|M|$ is constant. Consider now change - wlog an increase - in $|M|$. Define $m$ as the index of the lowest bilateral iceberg trade cost outside the set of trade partners, i.e. $m=\operatorname{argmin}_{k \in I \backslash M}\left\{\tau_{1 k}\right\}$. Whenever $|M|$ increases condition $\sqrt{\tau_{1 m}}=c_{11}+1$ must hold and equation (35) is satisfied for both of the two sets $M$ and $M \cup\{m\}$, implying that $c_{11}$ is continuous. This proves that $c_{11}$ is increasing in $\alpha /(\beta L)$.

Proposition 2 shows that the rise in trade share and the expansion of the set of trade partners are jointly driven by growth of marginal productivity. If the effect of this joint determinant is strong, it can induce a strong positive correlation between the rises in trade volumes and the number of source countries as exhibited by the data (see Figures 1 to 2). Moreover, it implies the common dynamics between per capita income and trade volumes (see, e.g., Hufbauer (1970) and Ventura (2006)).

At this point, it is worth to remember that the standard models fail to address these patterns of the trade data, so that the results presented in Proposition 2 constitute an improvement in reconciling the theory with the data. The sole departure from the standard setup was to assume that consumers derive only bounded marginal utility from varieties at zero consumption levels. Finally, to check that these results are qualitatively important it is worth evaluating how the model performs quantitatively.

\subsubsection{Calibration Exercise}

To assess how the model performs quantitatively, a symmetric version is calibrated to US trade data; the number of countries is 20 . This choice requires a word of justification. On the one hand, models that reflect relative economic sizes do better in predicting trade 
volumes since the share of world output is a key determinant of a country's trade volume (see , e.g., Anderson (1979)). On the other side, the number of source countries is a key variable of the present paper's model, which requires the number of potential trade partners to be relatively large. With a sufficiently large set of countries, however, the calibration of the asymmetric multi-country model cumbersome and intransparent. For this reason, I resume to the symmetric model.

Imposing symmetry is of course a heavy simplification. Yet, in defense of this assumption one may remember that relative per capita income between countries is very stable in the long run (see Acemoglu and Ventura (2002)) and that, as long as PPP holds, real exchange rates do not change dramatically (see, e.g., Froot and Rogoff (1996) or Wu (1996)). Since, finally, the ultimate channel through which country size affects trade volumes operates through terms of trade movements, these observations suggest that the error of imposing symmetry be limited. Thus, as a compromise that accounts for the number of source countries as well as for trade volumes, the world is assumed to consist of 20 countries - a choice that reflects the US share of world population, ranging around $5 \%$ throughout the time interval considered.

Turing to the calibration itself, the parameter $\alpha$ is normalized to one and the units for population $L$ are set to millions. Both choices inflict no loss of generality since the ratio $\alpha /(\beta L)$ is the only relevant variable for the calibration of the number of trade partners $|M|$ and trade shares $e$ (see Proposition 2). Hence, the model is left with the parameters $\beta, \gamma$ and trade costs $\tau_{1 k}$, which are to be calibrated to US data. Key time series are US non-oil import share and imported varieties, both derived from data as described in Feenstra et al (2002).

The calibration follows Yi (2003) to match the US trade share in the initial period (1972) with the choice of parameter $\gamma$. Similarly, the trade share of the final period (2000) is matched with the adequate choice of the initial productivity parameter $\beta_{1972} \cdot{ }^{14}$ This leads to $\gamma=0.15$ and $\beta_{1972}=14.39$. Next, population size and per capita income are from Penn World Tables 6.2. The latter series is used to proxy growth in marginal productivity $(1 / \beta)$.

Bilateral trade costs are assumed to be the sum of trade-weighted tariffs (taken from Feenstra et al (2002)) and the cif/fob measure (from the IMF International Financial Statistics). Anderson and van Wincoop (2004) estimate an ad valorem border cost of $40 \%$, which is added. Total trade costs are assumed to be additive between tariffs $t$ and transportation cost $\delta$ and are assumed to take the form $\tau_{m}=1.4+t+\delta(m /(M-1))^{\sigma}$. The functional form of the last term is chosen to fit the US bilateral trade cost data from 1989 to 2000 for 20 trade partners with the largest export volume to the US (data

\footnotetext{
${ }^{14}$ The joint choice of $\alpha$ and $\beta$ determines consumption units; compare also footnote 6 .
} 


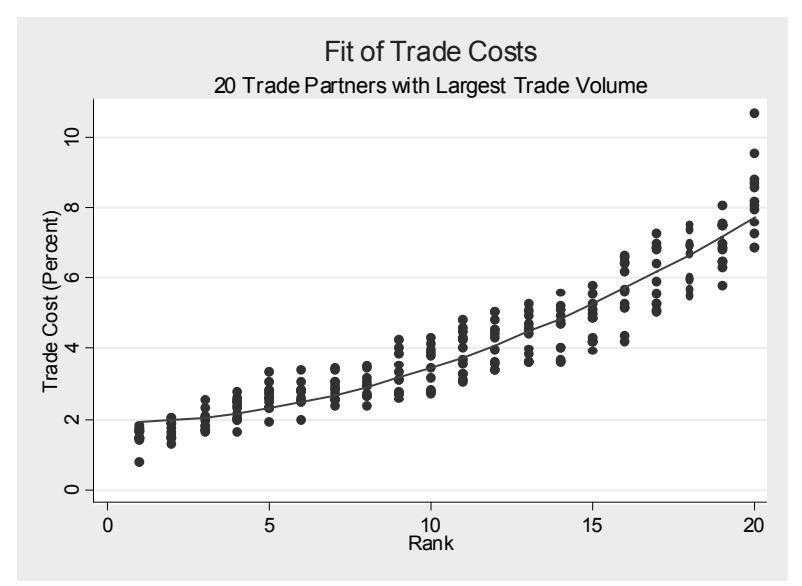

Figure 4: Trade cost for US trade partners with largest exports to US.

described in Feenstra et al (2002)). ${ }^{15}$. Figure 4 shows that this functional form provides a good fit for the trade costs data. The parameter $\sigma$ is chosen so as to maximize the fit and is set to $\sigma=1.9$ (the corresponding adjusted R-square including time dummies is 0.897 ) For each period, the value $\delta$ is chosen so that the cif/fob measure implied by the model coincides with the data. Table 1 summarizes the calibration of the key parameters; time series of population, per capita income, tariffs and trade costs are listed in the Appendix.

\begin{tabular}{|c|c|}
\hline model & value \\
\hline$\alpha$ & 1.00 \\
\hline$\beta$ & 14.39 \\
\hline$\gamma$ & 0.15 \\
\hline$\sigma$ & 1.90 \\
\hline
\end{tabular}

Table 1: Parameter values; calibrated to 20-country model.

As stated above, the model is calibrated to match the increase in trade shares so that its success in matching the data will be assessed along two main dimensions. The first dimension concerns the implied import elasticity. Yi (2003) puts forward that the increases in world trade volumes imply an excessive import elasticity in conventional models. Thus, import elasticity with respect to tariffs is a parameter of key interest in the calibration. It is here defined by

$$
\mathcal{E}=-(1+t) \frac{d}{d t} \ln (Q)
$$

where $Q$ stands for the total imported quantity. With prices (9), the optimal consumer

\footnotetext{
${ }^{15}$ A list of countries is in the Appendix. Data on bilateral trade costs as in Feenstra et al (2002) are available only for the period 1989-2000, wherefore this data source of trade costs is not used directly.
} 


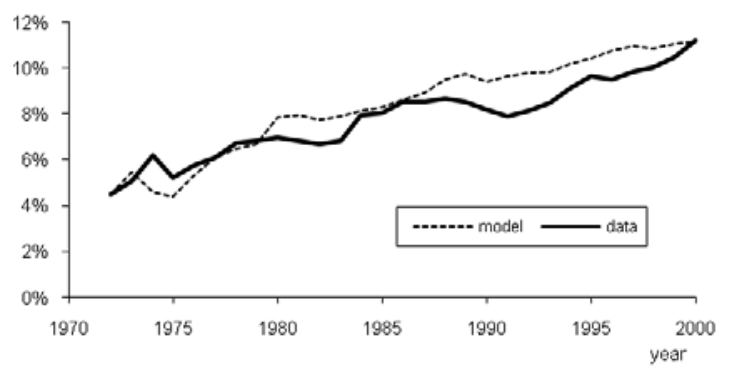

Varieties Imported by US

(1972 - 2000, normalized)

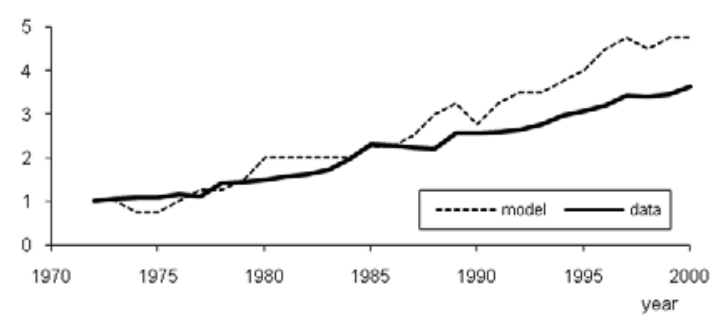

Figure 5: Data vs Model: Import Shares (top panel) and Number of Varieties (bottom panel).

choice (34), and the number of firms (38) this is

$$
Q=n \sum_{M \backslash\{1\}} c_{1 k}=\left(\frac{\left(c_{11}+1\right) \sum_{M \backslash\{1\}} \frac{1}{\sqrt{\tau_{1 k}}}-(M-1)}{\alpha+\beta L\left[c_{11}\left(T_{M, 1}+M\right)-T_{M, 2}-T_{M, 1}\right]}\right)
$$

With this definition, the implied import elasticity has a time-average of 3.7 with a peak of 8.8 at the start of the period and a minimum of 1.75 at the end of it. While the variation is arguably high, this time-average is close to the interval [2,3], which Yi (2003) puts forward as a realistic range. At the same time, the top panel of Figure 5 shows that the model's track of trade shares is reasonably close.

The second dimension along which the model should perform is the number of source countries. The bottom panel of Figure 5 graphs the number of imported varieties, defined as goods differentiated by country of origin (values are normalized to one at the initial period $)^{16}$. The model's prediction exceed the data by a factor of 1.4. This prediction not terribly precise but neither is it completely off the mark. For a stylized and dramatically simplified model its overall performance is reasonably satisfying.

\footnotetext{
${ }^{16}$ As in Broda and Weinstein (2004), varieties are defined as good differentiated by country of origin. Data are as described in Feenstra et al (2002). Good categories are different from those underlying Figures 1 and 2. In particular, they rely on TSUSA classification for the years from 1972 to 1988 and HS classification from 1989 to 2000.
} 
In sum, the model can explain two strong and important trends of trade data at reasonable parameter values: first, the massive growth of trade shares at a modest fall of trade costs and second the small fraction of trade relations that the average country engages in. It suggests technological progress as the core determinant of both variables and thereby generates two additional patterns of international trade data: first, the correlation between trade shares and per capita income and second, the correlation between the increases of trade volumes and the number of source countries.

\subsection{Discussion}

Before closing this section, a discussion two important aspects of the model is needed. The first one concerns the nature of productivity growth, which was assumed to affect marginal productivity only and leave entry cost unchanged. To some extend, the model's direct implication that stronger increasing returns (i.e. a higher ratio of setup cost over marginal cost) imply larger trade volumes is confirmed empirically in a cross section analysis by Harrigan (1994). The key question whether it is valid to assume productivity growth is biased towards marginal productivity can be answered with data on the total number of firms: a glance at time series of the number of US firms for the period 1988 to 2006 shows that the number of firms over population remains remarkably stable throughout this period, covering a large part of the calibration window. ${ }^{17}$ Within the framework of the current model, this implies that the setup cost cannot drop dramatically: indeed, in the reference case of the closed economy, population growth and productivity growth, limited to $\beta$, imply that the number of firms (17) rose by $53 \%$, compared to $22 \%$ in the data throughout the period 1988 - 2006. If, instead, the setup cost $\alpha$ decreases by the same rate as $\beta$, the implied growth of the number of firms is $125 \%$ in the same period ${ }^{18}$. In sum, the limited increase in the number of firms contradicts a substantial drop in setup costs. This observation lends additional support to the assumption that productivity growth occurs at the margin mainly and justifies the presumption that $\alpha$ stays constant while $\beta$ falls.

The second general remark concerns previous attempts to evaluate the effect of nonhomothetic preferences on trade volumes. These effects are generally estimated to be small (see Bergstrand (1990) and Bergoeing and Kehoe (2003), among others). These quantitative studies, however, are based on Stone-Geary type preferences between a ho-

\footnotetext{
${ }^{17}$ With data are from "United States Small Business Administration" (see http://www.sba.gov/advo/index.html), the number of firms per thousand US citizens oscillates between 19.5 and 20.1 between 1988 and 2006. Throughout the same time interval the number of employees per firm rises by $12.3 \%$ from 17.7 to 19.9 .

${ }^{18}$ The traditional Krugman (1980) model predicts that the number of firms is proportional to $L / \alpha$, independently of $\beta$ trade openness. In this setting, the population growth (23\%) between 1988 and 2006 implied that the setup cost rose by $1 \%$ if the observed increase in the number of firms $(22 \%)$ was to be matched.
} 
mogeneous good and a composite of varieties. As such, they impose by construction that the expenditure share on the intensively traded good rises with per capita income. The present paper, instead, starts from the premises that all varieties are identical and trade costs endogenously introduce a bias to local goods, which decreases with increasing income. Yet, whether the current model performs better in empirical test remains to be seen. In any case, the Stone-Geary type approach suffers from the above-mentioned drawback that any country with positive trade shares imports all tradable varieties from all other trading countries. Consequently, the according models rule out the existence of a non-trivial fraction of imported varieties over world tradables, thereby failing to explain an endogenous expansion of the set of trade partners and missing one channel through which trade volumes expand.

\section{Conclusion}

This paper has shown that a small and realistic twist in the demand structure of the Krugman (1980) model goes a long way in explaining four strong and important empirical regularities. These empirical patterns are (i) countries import only a small fraction of all traded varieties (ii) per capita income and the number of imported varieties correlate positively (iii) per capita income and trade shares correlate positively and, finally, (iv) world trade shares have increased substantially. These patterns are both, well known and well studied. By the paper's key assumption marginal utility derived from each variety is bounded. This implies that varieties whose transport is very costly drop out of the individual's consumption basket. Technological progress that induces a higher per capita consumption of those varieties already consumed decreases the marginal utility derived from them and makes consumers expand their consumption basket towards more expensive, foreign varieties. Therefore, such technological progress drives up the number of source countries per good, the trade share, and per capita income. 


\section{A Lists and Tables}

\section{List of largest US trade partners - Figures 1 and 2}

(Data as described in Feenstra et al (2005))

Afghanistan, Algeria, Argentina, Australia, Austria, Bahamas, Bahrain, Barbados, Belgium, Belize, Benin, Bermuda, Bolivia, Brazil, Burkina Faso, Burundi, Cambodia, Cameroon, Canada, Central African Rep., Chad, Chile, China, Hong Kong, Macao, Colombia, Congo, Costa Rica, Cote D'Ivoire, Cuba, Cyprus, Dem. Rep. Congo, Denmark, Dominican Rep., Ecuador, Egypt, El Salvador, Eq. Guinea, Ethiopia, Fiji, Finland, France, Gabon, Gambia, Ghana, Greece, Guatemala, Guinea, Guinea Bissau, Haiti, Honduras, Hungary, Iceland, Indonesia, Iran, Iraq, Ireland, Israel, Italy, Jamaica, Japan, Jordan, Kenya, Kiribati, North Korea, South Korea, Kuwait, Liberia, Madagascar, Malawi, Malaysia, Mali, Malta, Mauritania, Mauritius, Mexico, Mongolia, Morocco, Mozambique, Nepal, Neth. Ant. Aruba, Netherlands, New Zealand, Nicaragua, Niger, Nigeria, Norway, Oman, Pakistan, Panama, Papua New Guinea, Paraguay, Peru, Philippines, Poland, Portugal, Qatar, Romania, Rwanda, Samoa, Saudi Arabia, Senegal, Sierra Leone, Singapore, Somalia, South Africa, Spain, Sri Lanka, St. Kt-Nev-An, Sudan, Suriname, Sweden, Switzerland, Syria, Taiwan, Tanzania, Thailand, Togo, Trinidad and Tobago, Tunisia, Turkey, UK, USA, Uganda, UAE, Uruguay, Venezuela, Zambia, Zimbabwe.

\section{List of 20 largest US trade partners (1989-2000) - Figure 5}

(Data as described in Feenstra et al (2002))

Belgium, Brazil, Canada, China, France, Germany, Hongkong, Indonesia, Italy, Japan, Korea, Malaysia, Mexico, Netherlands, Philippines, Singapor, Switzerland, Taiwan, Thailand, UK. 


\begin{tabular}{|c|cccc||}
\hline \hline year & Popul. (mio) & $\begin{array}{c}\text { Growth of } \\
\text { Income p.c. } \\
(\%)\end{array}$ & cif/fob (\%) & Tariff (\%) \\
\hline 1972 & 209.90 & & 5.90 & 5.89 \\
1973 & 211.91 & 4.89 & 5.90 & 4.52 \\
1974 & 213.85 & -1.46 & 6.93 & 3.21 \\
1975 & 215.97 & -1.32 & 6.62 & 3.74 \\
1976 & 218.04 & 4.64 & 6.33 & 3.28 \\
1977 & 220.24 & 3.65 & 5.86 & 3.39 \\
1978 & 222.59 & 4.46 & 5.68 & 3.73 \\
1979 & 225.06 & 2.08 & 5.68 & 3.51 \\
1980 & 227.73 & -1.41 & 4.78 & 2.87 \\
1981 & 229.97 & 1.45 & 4.74 & 3.05 \\
1982 & 232.19 & -3.00 & 4.48 & 3.58 \\
1983 & 234.31 & 3.39 & 4.58 & 3.22 \\
1984 & 236.35 & 6.35 & 4.74 & 3.42 \\
1985 & 238.47 & 2.89 & 4.74 & 3.57 \\
1986 & 240.65 & 2.44 & 4.61 & 3.62 \\
1987 & 242.80 & 2.44 & 4.48 & 3.68 \\
1988 & 245.02 & 3.22 & 4.22 & 3.62 \\
1989 & 247.34 & 2.53 & 4.17 & 3.42 \\
1990 & 250.13 & 0.61 & 4.38 & 3.35 \\
1991 & 253.49 & -1.82 & 4.08 & 3.25 \\
1992 & 256.89 & 1.70 & 3.99 & 3.24 \\
1993 & 260.26 & 1.35 & 3.95 & 3.19 \\
1994 & 263.44 & 2.82 & 3.82 & 3.01 \\
1995 & 266.56 & 0.98 & 3.67 & 2.58 \\
1996 & 269.67 & 3.26 & 3.36 & 2.32 \\
1997 & 272.91 & 3.26 & 3.27 & 2.05 \\
1998 & 276.12 & 2.97 & 3.56 & 2.00 \\
1999 & 279.29 & 2.68 & 3.40 & 1.78 \\
2000 & 282.34 & 3.12 & 3.39 & 1.63 \\
\hline & & & & \\
\hline
\end{tabular}

Table 2. Time series of calibration input.

\begin{tabular}{||c|cc|cc|c||}
\hline & \multicolumn{2}{|c|}{ Number of Varieties } & \multicolumn{2}{|c||}{ Import Share } & Elasticity \\
\hline year & model & data & model & data & model \\
\hline 1972 & 1.00 & 1.00 & $4.50 \%$ & $4.50 \%$ & 8.82 \\
1973 & 1.00 & 1.05 & $5.47 \%$ & $5.08 \%$ & 5.79 \\
1974 & 0.75 & 1.09 & $4.57 \%$ & $6.21 \%$ & 6.51 \\
1975 & 0.75 & 1.08 & $4.39 \%$ & $5.24 \%$ & 7.13 \\
1976 & 1.00 & 1.16 & $5.32 \%$ & $5.75 \%$ & 6.08 \\
1977 & 1.25 & 1.10 & $6.10 \%$ & $6.12 \%$ & 5.34 \\
1978 & 1.25 & 1.41 & $6.51 \%$ & $6.72 \%$ & 4.53 \\
1979 & 1.50 & 1.42 & $6.71 \%$ & $6.82 \%$ & 4.79 \\
1980 & 2.00 & 1.48 & $7.87 \%$ & $6.97 \%$ & 3.89 \\
1981 & 2.00 & 1.56 & $7.95 \%$ & $6.82 \%$ & 3.78 \\
1982 & 2.00 & 1.61 & $7.75 \%$ & $6.70 \%$ & 4.16 \\
1983 & 2.00 & 1.72 & $7.93 \%$ & $6.84 \%$ & 3.84 \\
1984 & 2.00 & 1.97 & $8.16 \%$ & $7.93 \%$ & 3.45 \\
1985 & 2.25 & 2.30 & $8.30 \%$ & $8.03 \%$ & 3.52 \\
1986 & 2.25 & 2.27 & $8.62 \%$ & $8.51 \%$ & 3.12 \\
1987 & 2.50 & 2.24 & $8.94 \%$ & $8.53 \%$ & 2.95 \\
1988 & 3.00 & 2.19 & $9.53 \%$ & $8.69 \%$ & 2.63 \\
1989 & 3.25 & 2.55 & $9.77 \%$ & $8.53 \%$ & 2.50 \\
1990 & 2.75 & 2.56 & $9.42 \%$ & $8.19 \%$ & 2.59 \\
1991 & 3.25 & 2.57 & $9.66 \%$ & $7.92 \%$ & 2.65 \\
1992 & 3.50 & 2.63 & $9.81 \%$ & $8.16 \%$ & 2.60 \\
1993 & 3.50 & 2.77 & $9.88 \%$ & $8.46 \%$ & 2.54 \\
1994 & 3.75 & 2.98 & $10.21 \%$ & $9.11 \%$ & 2.31 \\
1995 & 4.00 & 3.08 & $10.45 \%$ & $9.64 \%$ & 2.19 \\
1996 & 4.50 & 3.19 & $10.80 \%$ & $9.50 \%$ & 2.02 \\
1997 & 4.75 & 3.42 & $10.98 \%$ & $9.85 \%$ & 1.92 \\
1998 & 4.50 & 3.41 & $10.90 \%$ & $10.03 \%$ & 1.92 \\
1999 & 4.75 & 3.46 & $11.08 \%$ & $10.46 \%$ & 1.83 \\
2000 & 4.75 & 3.63 & $11.18 \%$ & $11.20 \%$ & 1.75 \\
\hline & & & & & \\
\hline
\end{tabular}

Table 3. Time series - data and calibration output. 


\section{B References}

Acemoglu, D and J. Ventura 2002: "The World Income Distribution" Quarterly Journal of Economics, Vol. 117 (2), pp. 659-694

Alcalá, F and Ciccone, A. 2004: "Trade and Productivity" Quarterly Journal of Economics, Vol. 119 (2), pp. 613-646.

Anderson J. 1979: "A Theoretical Foundation of the Gravity Equation" American Economic Review, Vol. 69, 1, pp. 106-116

Anderson J. and van Wincoop E. 2003: "Gravity with Gravitas: A Solution to the Border Puzzle" American Economic Review, Vol. 93, 1, pp. 170-192

Anderson J. and van Wincoop E. 2004: "Trade Costs" Journal of Economic Literature, Volume 42, No. 3, pp. 691-751

Baier, S. and Bergstrand, J. 2001: "The Growth of World Trade: Tariffs, Transport Costs, and Income Similarity" Journal of International Economics, Vol. 53, pp. 1-27

Bergoeing R., Kehoe T. J., Strauss-Kahn V., and Yi K-M 2004: "Why Is Manufacturing Trade Rising Even as Manufacturing Output is Falling?" American Economic Review, 94, pp. $134-138$

Bergoeing R. and Kehoe T. J. 2003: "Trade Theory and Trade Facts" Federal Reserve Bank of Minneapolis, Research Department Staff Report 284

Bergstrand, Jeffrey H. 1989: "The Generalized Gravity Equation, Monopolistic Competition, and the Factor-Proportions Theory in International Trade" The Review of Economics and Statistics, Vol. 71 (1), pp. 143-153

Bergstrand, J. 1990: "The Heckscher-Ohlin-Samuelson Model, the Linder Hypothesis, and the Determinants of Bilateral Intra-Industry Trade" Economic Journal, Vol. 100, pp. 1216-1229

Broda, Christian and Weinstein, David E. 2004: "Variety Growth and World Welfare" American Economic Review, Vol. 94, 2, pp. 139-144

Broda, Christian and Weinstein, David E. 2006: "Globalization and the Gains From Variety" Quarterly Journal of Economics, Vol. 121 (2), pp. 541-585

Chaney, T. 2008: "Distorted Gravity: The Intensive and Extensive Margins of International Trade," American Economic Review, Vol. 98 (4), pp. 1707-1721

Cuñat, A., and Maffezzoli, M. 2007: "Can Comparative Advantage Explain the Growth of US Trade?" Economic Journal Vol. 117 pp. 583-602 
Eaton, J. and Kortum, S. 2002: "Technology, Geography, and Trade" Econometrica Vol. 70, No. 5, pp. 1741-1779

Frankel, J. and Romer, D. 1999: "Does Trade Cause Growth?" American Economic Review, Vol. 89, pp. 379-399.

Feenstra, R., Romalis, J., and Schott, P. 2002. "U.S. Imports, Exports and Tariff Data 1989-2001" NBER WP 9387.

Feenstra, R., Lipsey, R., Deng, H., Ma, A., and Mo, H. 2005: "World Trade Flows 19622000" NBER WP 11040.

Foellmi, R. and Zweimüller, J. 2006: "Income Distribution and Demand-Induced Innovations" Review of Economic Studies 73 (4), pp. 941-960.

Francois, J and Kaplan, S. 1996: "Aggregate Demand Shifts, Income Distribution, and the Linder Hypothesis" Review of Economics and Statistics, vol. 78, (2) pp. 244-250

Froot, K. and Kenneth Rogoff, K.: "Perspectives on PPP and Long-Run Real Exchange Rates" in G. Grossman and K. Rogoff (eds.) Handbook of International Economics, Vol. 3 Amsterdam, North-Holland (1995)

Hallak, J. C. 2006: "Product Quality and the Direction of Trade" Journal of International Economics Vol. 68 238-265

Harrigan, J. 1994: "Scale Economies and the Volume of Trade" Review of Economics and Statistics, vol. 76, pp. 321-328

Helpman, E., Melitz, M. and Rubinstein, Y. 2008: "Estimating Trade Flows: Trading Partners and Trading Volumes," Quarterly Journal of Economics, Vol. 123 (2), pp. 441487

Haveman, J. and Hummels, D., 2004: "Alternative Hypothesis and the Volume of Trade: Evidence on the Extent of Specialization", Canadian Journal of Economics, Vol. 37, pp. 199-218

Hufbauer, G.: "The impact of National Characteristics and Technology on the Commodity Composition of Trade" in R. Vernon (ed.) The Technology Factor in International Trade, New York, Columbia University Press, 1970

Hummels, D., and Klenow, P. J., 2005: "The Variety and Quality of a Nation's Exports" American Economic Review, 93, 3, pp. 704-723

Hummels, D., Lugovsky, V., 2005: "Trade in Ideal Varieties: Theory and Evidence" NBER WP No. 11828. 
Hunter, L. C., and Markusen, J. R.: "Per-Capita Income As a Determinant of Trade", in Feenstra, R. (ed.) Empirical Methods for International Trade, MIT Press 1988

Kehoe, T. and Ruhl, K. 2002: "How Important is the New Goods Margin in Internatioanl Trade?" Staff Report 324, Federal Reserve Bank of Minneapolis

Krugman, P. 1980: "Scale Economies, Product Differentiation, and the Pattern of Trade" American Economic Review, 70, pp. 950-959

Krugman, P. 1995: "Growing World Trade: Causes and Consequences" Brookings Papers on Economic Activity, 1, pp. 327-376

Matsuyama, K. 2000: "A Ricardian Model with a Continuum of Goods under Nonhomothetic Preferences: Demand Complementarities, Income Distribution, and North-South Trade" Journal of Political Economy, Vol. 108 (6), pp. 1093-1120

Melitz, M. 2003: "The Impact of Trade on Intra-Industry Reallocations and Aggregate Industry Productivity" Econometrica Vol. 71, No. 6, pp. 1695-1725

Melitz, M. and Ottaviano, G. 2008: "Market Size, Trade, and Productivity," Review of Economic Studies, Vol. 75 (1), pp. 295-316

Ruhl, K. 2005: "Solving the Elasticity Puzzle in International Economics" mimeo University of Texas at Austin

Schott, Peter K. 2004. "Across-Product versus Within-Product Specialization in International Trade," Quarterly Journal of Economics, Vol. 119 (2), pp. 647-678.

Simonovska, I. 2009: "Income Differences and Prices of Tradables," mimeo University of Minnesota

Thursby, J. G. and Thursby, M. C. 1987: "Bilateral Trade Flows, the Linder Hypothesis, and Exchange Risk" Review of Economics and Statistics, Vol. 69, No. 3, pp. 488-495

Ventura, J. 2006: "A Global View of Economic Growth" Handbook of Economic Growth, vol. 1B, Aghion P. and Durlauf S. N. (eds.), Elsevier B. V.

Wu, Y. 1996: "Are Real Exchange Rates Nonstationary? Evidence from Panel Data Tests," Journal of Money, Credit \& Banking, Vol. 28 (1), pp. 54-63

Yi, K.-M. 2003: "Can Vertical Specialization Explain the Growth of World Trade?" Journal of Political Economy, Vol. 111, No.1, pp. 52-102

Young, A. 1991: "Learning by Doing and the Dynamic Effects of International Trade" Quarterly Journal of Economics, Vol. 106, No. 2, pp. 369-405 


\section{Swiss National Bank Working Papers published since 2004:}

2004-1 Samuel Reynard: Financial Market Participation and the Apparent Instability of Money Demand

2004-2 Urs W. Birchler and Diana Hancock: What Does the Yield on Subordinated Bank Debt Measure?

2005-1 Hasan Bakhshi, Hashmat Khan and Barbara Rudolf: The Phillips curve under state-dependent pricing

2005-2 Andreas M. Fischer: On the Inadequacy of Newswire Reports for Empirical Research on Foreign Exchange Interventions

2006-1 Andreas M. Fischer: Measuring Income Elasticity for Swiss Money Demand: What do the Cantons say about Financial Innovation?

2006-2 Charlotte Christiansen and Angelo Ranaldo: Realized Bond-Stock Correlation: Macroeconomic Announcement Effects

2006-3 Martin Brown and Christian Zehnder: Credit Reporting, Relationship Banking, and Loan Repayment

2006-4 Hansjörg Lehmann and Michael Manz: The Exposure of Swiss Banks to Macroeconomic Shocks - an Empirical Investigation

2006-5 Katrin Assenmacher-Wesche and Stefan Gerlach: Money Growth, Output Gaps and Inflation at Low and High Frequency: Spectral Estimates for Switzerland

2006-6 Marlene Amstad and Andreas M. Fischer: Time-Varying Pass-Through from Import Prices to Consumer Prices: Evidence from an Event Study with Real-Time Data

2006-7 Samuel Reynard: Money and the Great Disinflation

2006-8 Urs W. Birchler and Matteo Facchinetti: Can bank supervisors rely on market data? A critical assessment from a Swiss perspective

2006-9 Petra Gerlach-Kristen: A Two-Pillar Phillips Curve for Switzerland

2006-10 Kevin J. Fox and Mathias Zurlinden: On Understanding Sources of Growth and Output Gaps for Switzerland

2006-11 Angelo Ranaldo: Intraday Market Dynamics Around Public Information Arrivals

2007-1 Andreas M. Fischer, Gulzina Isakova and Ulan Termechikov: Do FX traders in Bishkek have similar perceptions to their London colleagues? Survey evidence of market practitioners' views 
2007-2 Ibrahim Chowdhury and Andreas Schabert: Federal Reserve Policy viewed through a Money Supply Lens

2007-3 Angelo Ranaldo: Segmentation and Time-of-Day Patterns in Foreign Exchange Markets

2007-4 Jürg M. Blum: Why ‘Basel II’ May Need a Leverage Ratio Restriction

2007-5 Samuel Reynard: Maintaining Low Inflation: Money, Interest Rates, and Policy Stance

2007-6 Rina Rosenblatt-Wisch: Loss Aversion in Aggregate Macroeconomic Time Series

2007-7 Martin Brown, Maria Rueda Maurer, Tamara Pak and Nurlanbek Tynaev: Banking Sector Reform and Interest Rates in Transition Economies: Bank-Level Evidence from Kyrgyzstan

2007-8 Hans-Jürg Büttler: An Orthogonal Polynomial Approach to Estimate the Term Structure of Interest Rates

2007-9 Raphael Auer: The Colonial Origins Of Comparative Development: Comment. A Solution to the Settler Mortality Debate

2007-10 Franziska Bignasca and Enzo Rossi: Applying the Hirose-Kamada filter to Swiss data: Output gap and exchange rate pass-through estimates

2007-11 Angelo Ranaldo and Enzo Rossi: The reaction of asset markets to Swiss National Bank communication

2007-12 Lukas Burkhard and Andreas M. Fischer: Communicating Policy Options at the Zero Bound

2007-13 Katrin Assenmacher-Wesche, Stefan Gerlach, and Toshitaka Sekine: Monetary Factors and Inflation in Japan

2007-14 Jean-Marc Natal and Nicolas Stoffels: Globalization, markups and the natural rate of interest

2007-15 Martin Brown, Tullio Jappelli and Marco Pagano: Information Sharing and Credit: Firm-Level Evidence from Transition Countries

2007-16 Andreas M. Fischer, Matthias Lutz and Manuel Wälti: Who Prices Locally? Survey Evidence of Swiss Exporters

2007-17 Angelo Ranaldo and Paul Söderlind: Safe Haven Currencies 
2008-1 Martin Brown and Christian Zehnder: The Emergence of Information Sharing in Credit Markets

2008-2 Yvan Lengwiler and Carlos Lenz: Intelligible Factors for the Yield Curve

2008-3 Katrin Assenmacher-Wesche and M. Hashem Pesaran: Forecasting the Swiss Economy Using VECX* Models: An Exercise in Forecast Combination Across Models and Observation Windows

2008-4 Maria Clara Rueda Maurer: Foreign bank entry, institutional development and credit access: firm-level evidence from 22 transition countries

2008-5 Marlene Amstad and Andreas M. Fischer: Are Weekly Inflation Forecasts Informative?

2008-6 Raphael Auer and Thomas Chaney: Cost Pass Through in a Competitive Model of Pricing-to-Market

2008-7 Martin Brown, Armin Falk and Ernst Fehr: Competition and Relational Contracts: The Role of Unemployment as a Disciplinary Device

2008-8 Raphael Auer: The Colonial and Geographic Origins of Comparative Development

2008-9 Andreas M. Fischer and Angelo Ranaldo: Does FOMC News Increase Global FX Trading?

2008-10 Charlotte Christiansen and Angelo Ranaldo: Extreme Coexceedances in New EU Member States' Stock Markets

2008-11 Barbara Rudolf and Mathias Zurlinden: Measuring capital stocks and capital services in Switzerland

2008-12 Philip Sauré: How to Use Industrial Policy to Sustain Trade Agreements

2008-13 Thomas Bolli and Mathias Zurlinden: Measuring growth of labour quality and the quality-adjusted unemployment rate in Switzerland

2008-14 Samuel Reynard: What Drives the Swiss Franc?

2008-15 Daniel Kaufmann: Price-Setting Behaviour in Switzerland - Evidence from CPI Micro Data

2008-16 Katrin Assenmacher-Wesche and Stefan Gerlach: Financial Structure and the Impact of Monetary Policy on Asset Prices

2008-17 Ernst Fehr, Martin Brown and Christian Zehnder: On Reputation: A Microfoundation of Contract Enforcement and Price Rigidity 
2008-18 Raphael Auer and Andreas M. Fischer: The Effect of Low-Wage Import Competition on U.S. Inflationary Pressure

2008-19 Christian Beer, Steven Ongena and Marcel Peter: Borrowing in Foreign Currency: Austrian Households as Carry Traders

2009-1 Thomas Bolli and Mathias Zurlinden: Measurement of labor quality growth caused by unobservable characteristics

2009-2 Martin Brown, Steven Ongena and Pinar Yeșin: Foreign Currency Borrowing by Small Firms

2009-3 Matteo Bonato, Massimiliano Caporin and Angelo Ranaldo: Forecasting realized (co)variances with a block structure Wishart autoregressive model

2009-4 Paul Söderlind: Inflation Risk Premia and Survey Evidence on Macroeconomic Uncertainty

2009-5 Christian Hott: Explaining House Price Fluctuations

2009-6 Sarah M. Lein and Eva Köberl: Capacity Utilisation, Constraints and Price Adjustments under the Microscope

2009-7 Philipp Haene and Andy Sturm: Optimal Central Counterparty Risk Management

2009-8 Christian Hott: Banks and Real Estate Prices

2009-9 Terhi Jokipii and Alistair Milne: Bank Capital Buffer and Risk Adjustment Decisions

2009-10 Philip Sauré: Bounded Love of Variety and Patterns of Trade 
Swiss National Bank Working Papers are also available at www.snb.ch, section Publications/Research Subscriptions or individual issues can be ordered at Swiss National Bank, Fraumünsterstrasse 8, CH-8022 Zurich, fax+41 4463181 14, E-mail library@snb.ch 